\title{
Э.Е. Шумилова
}

\section{ПЕРВАЯ МИРОВАЯ ВОЙНА И УРОВЕНЬ МЕДИЦИНСКОГО ОБСЛУЖИВАНИЯ НАСЕЛЕНИЯ В КРУПНЫХ ГОРОДАХ ЗАПАДНОЙ СИБИРИ (1914-1917 гг.)}

\begin{abstract}
Анализируется уровень медицинского обслуживания населения в крупных городах Западной Сибири в 1914-1917 гг. На основе вводимых в научный оборот архивных источников делается вывод о том, что в годы Первой мировой войны в Омске, Томске, Новониколаевске и Барнауле оно было организовано на неудовлетворительном уровне. Горожане столкнулись с загруженностью лечебных учреждений военнопленными и беженцами, а также военнообязанными, для которых изначально не было построено достаточно лечебных учреждений. С первого года войны сибирские города захлестнули многочисленные эпидемии заразных заболеваний, источником которых часто были вышеупомянутые социальные группы. Среди причин возникновения неблагоприятной эпидемической обстановки автор выделяет: недостаток врачей, медикаментов и медицинских инструментов вследствие ухода персонала на войну и прекращения импорта из заграницы, антисанитарные условия проживания вынужденных переселенцев, плохое питание больных, а также недофинансирование лечебных заведений. Вместе с тем подчёркивается, что сибирские врачи и местные власти предпринимали ряд эффективных мер по борьбе с заразными заболеваниями и смогли предотвратить более масштабные эпидемии.

Ключевые слова: медицина; эпидемия; Западная Сибирь; Первая мировая война; Новониколаевск; Барнаул; Томск; Омск.
\end{abstract}

Интерес к истории медицинского обслуживания населения в Западной Сибири в годы Первой мировой войны начал проявляться ещё у дореволюционных исследователей. В основном это были небольшие по объему очерки об отдельных лечебных учреждениях или статьи специалистов-медиков по вопросам медицинской науки и практики $[1,2]$. В советский период продолжилось изучение этого вопроса. Появились работы, посвящённые как изучению отдельных лечебных заведений, так и истории медицины в Сибири в целом, в которых освещался дореволюционный период [3-5]. В постсоветское время впервые появляются статьи и объёмные труды по истории проблемы, написанные профессиональными историками. В современных работах предпринимается попытка охарактеризовать деятельность в области борьбы с эпидемиями заразных заболеваний в изучаемый период, проанализировать работу отдельных медицинских учреждений или даже комплексно охарактеризовать уровень развития здравоохранения в отдельных крупных городах Западной Сибири [6-10].

Однако большинство современных исследований посвящено военной медицине или заботе о больных и раненых воинах, а период Первой мировой войны в развитии гражданской медицины в Западной Сибири отдельно не выделяется и, следовательно, не формулируются выводы о том, как война повлияла на медицинское обеспечение горожан, оставшихся в тылу.

Первая мировая война оказала огромное воздействие на все стороны жизни российского общества, обнаружив, в том числе, серьёзное влияние и на медицинское обеспечение населения Российской империи. В крупных тыловых городах, где наблюдалось наибольшее скопление беженцев и военнопленных, эти изменения были особенно заметны.

С начала войны больницы всех крупных городов Западной Сибири были переполнены больными. Так, по данным врачебно-санитарного бюро, в конце сен- тября - начале октября 1914 г. в Томске было зарегистрировано 50 заболевших, в том числе 18 больных дизентерией, 8 - брюшным тифом, 7 - скарлатиной и т.д. За неделю от острых заразных заболеваний скончались 8 человек [11]. В Новониколаевске за сентябрь и октябрь 1914 г. было зарегистрировано 238 заболевших, из которых 77 человек болели брюшным тифом [12. Л. 17-28]. В 1915 г. в Западной Сибири уже свирепствовали эпидемии. Согласно статистике, сыпным тифом в 1915 г. в Новониколаевке болели 4285 чел., из которых умерли 1094 [13. С. 211]. В Омске в 1915 г., по сравнению с 1914 г., количество случаев заболевания натуральной оспой увеличилось с 89 до 258 чел., корью - с 347 до 411 чел., скарлатиной - с 281 до 580 чел., дифтеритом - с 128 до 175 чел., брюшным тифом - с 212 до 597 чел., сыпным тифом - с 37 до 70 чел., дизентерией - с 13 до 204 чел., эпидемическим гастроэнтеритом - с 21 до 103 чел., рожей - с 56 до 144 чел. [14. С. 7]. Неблагоприятная ситуация была характерна и для Барнаула, который эпидемия сыпного тифа охватила в 1916 г. По данным доктора А.П. Велижанина, в Барнаульской городской заозерной больнице пик заболеваемости сыпным тифом пришёлся на январь 1916 г., когда там было зарегистрировано 125 больных [1. С. 230-231]. Летом 1916 г. в Томске началась эпидемия дизентерии: вместо 5-8 заболевших ранее за одну неделю конца июня заболели сразу 66 человек [15].

Оторванность во время войны женатых военнослужащих от своих семейств, недостаточный надзор за проституцией, а также приказ верховного начальника санитарной и эвакуационной части Российской империи А.П. Ольденбургского № 28, резко сокративший приём в госпитали пациентов с венерическими заболеваниями, привели в эти годы к массовым эпидемиям по всей стране [1. С. 177-178]. Не обошла эпидемия и Западную Сибирь. Так, например, по свидетельству врача Н.И. Плоскарева, в Томске в специальную городскую 
амбулаторию с утренними и вечерними приёмами ежедневно прибывали солдаты как местного гарнизона, так и с фронта с самыми заразными формами сифилиса и венерических болезней [1. С. 193].

Главными источниками распространения различных эпидемий опасных заболеваний среди местного населения были инфицированные пленные, беженцы и военнообязанные. В журнале очередного собрания Омской городской Думы за 3 марта 1915 г. читаем: «В связи с поселением в городе Омске австрийских и особенно турецких пленных в городе наблюдается распространение заразных болезней - оспы, сыпного и брюшного тифа и др., распространение, принимающее черты эпидемии» [16. Л. 168]. Население зачастую заражалось, покупая вещи у пленных, а также через врачей и медицинский персонал заразных больниц [17]. В протоколе совещания врачей Омска при Санитарном бюро отмечалось, что источником распространения сыпного тифа в 1915 г. среди жителей города, согласно материалам расследования, также стал Омский военный госпиталь [16. Л. 155].

Невероятная скученность среди беженцев в городах Западной Сибири серьёзно повышала вероятность эпидемических заболеваний среди них. Города принимали беженцев более того количества, чем могли принять. По пути следования медицинский надзор за ними почти отсутствовал, бывали случаи, что с поездов снимали мёртвых, т.е. не обнаруженные вовремя больные разносили заразу по всему пути их следования [14. C. 3].

Немалую роль также играли и антисанитарные условия сибирских городов. Описывая санитарное состояние барнаульской больницы, корреспондент газеты «Жизнь Алтая» отмечал: «Тут же около родильного отделения в коридоре помещены ящики с больничным бельём, а на ящиках узлы с одеждой больных: цейхгаузов не хватает, и, кроме того, в цейхгаузах одежда портится крысами. На кухне плита разваливается, готовить на кухни нельзя, и пища для больных и служебного персонала готовится на кухне заразного барака» [18]. Эпидемиологическую ситуацию в городах обостряли скученность проживания, очень маленькое количество общественных бань, дезинфекционных камер, дешёвых прачечных, а также отсутствие канализаций [19. С. 7].

К страданиям заболевших в городах Западной Сибири добавлялась и нехватка квалифицированной медицинской помощи. К началу ХХ в. Сибирь явно отставала по наличию медицинских работников от центральных губерний. На одного врача приходилось 14246 кв. верст и 11100 жителей в сравнении с 252 кв. верстами и 7100 чел. в европейской части России [20]. В 1916 г. на 80-тысячное население Новониколаевска приходилось несколько больниц: первая городская общего профиля с родильным отделением, вторая городская («заразная»), переселенческая, железнодорожная, участково-сельская, амбулатория в Закаменской части города и два приемных покоя. Кроме того, действовал лазарет на военно-остановочном пункте. Врачебная помощь была также организована в реальном училище и городских начальных школах, на казенном винном складе, военно-сухарном заводе и некоторых других наиболее крупных предприятиях, работали около десятка частных врачей [13. С. 367].

Медицинская помощь, которую могли предоставить больницы Омска, также не могла удовлетворить потребности постоянно растущего населения города. К 1916 г. в Омске, где проживали около 130 тыс. чел., существовали следующие лечебные учреждения: городская больница с четырьмя штатными врачами; городская амбулатория с двумя штатными врачами, которые также работали в городской больнице; областная лечебница для душевно-больных с одним штатным врачом на 19 мест; военный госпиталь с одним врачом; больница Омского переселенческого пункта с одним врачом; лечебница Омской Общины Красного Креста на 25 мест; больница доктора медицины А.И. Фогеля; убежище для рожениц; кроме того, осуществляли частную практику несколько десятков частных врачей [21. С. 92-97]. Самая большая в городе городская больница в 1916 г. имела инфекционное отделение на 60 мест, холерный барак, венерическую больницу, а также барак родильного дома, причём все места были заняты инфекционными больными [19. С. 7].

В Томске с населением в то время около 100 тыс. чел. ситуация с медицинскими кадрами была немного лучше, чем в других сибирских городах. Это объяснялось статусом губернского города и наличием Императорского Томского университета, который готовил будущих врачей. Однако большое количество жителей окрестных сёл и других регионов, обслуживаемых в больницах Томска, заметно сокращали это преимущество. В изучаемый период в городе находилось около десятка больниц. Среди них одна из пяти крупнейших психиатрических больниц Российской империи Окружная психиатрическая лечебница. Она насчитывала более 1000 кроватей и обслуживала, помимо томичей, жителей Томской, Иркутской, Енисейской губерний, а также Акмолинскую, Семипалатинскую и Забайкальскую области [22. С. 272].

Огромная губернская больница Ведомства Общественного Призрения с 10 штатными врачами также располагалась в Томске. Она насчитывала в 1914 г. 344 кровати, а к 1917 г. - уже 620 кроватей и девять отделений: хирургическое, терапевтическое, венерическое, заразное, детское, женское, дом для неизлечимых больных, богадельня, дом для умалишённых. В распоряжении больницы имелась также лаборатория для научных исследований. Через больницу Ведомства Общественного Призрения в 1914 г. прошли 3234 стационарных больных, в 1915 г. - 3 846, в 1916 г. - 3 684, амбулаторных больных было зарегистрировано в 1914 г.- 8145 чел., в 1915 г. - 8944 чел., а в 1916 г. 10694 чел. Чуть больше половины из них составляли собственно жители Томска [1. С. 209-210, 213]. В годы 
войны в Томске работали также клиники при Императорском Томском университете на 220 коек, которые занимались в основном интересными, с точки зрения университетских преподавателей, медицинскими случаями, всех остальных отправляли в больницу Ведомства Общественного Призрения [22. С. 269].

Кроме того, население амбулаторно обслуживала городская лечебница для бедных приходящих больных с тремя штатными врачами по общей амбулатории, венерическим и гинекологическим болезням; больница имени Ивана Некрасова с шестью штатными врачами для острых незаразных больных; железнодорожная больница на вокзале станции Томск-2, расчитанная на 70 коек и имеющая в своём штате двух врачей; амбулатория Сибирской железной дороги, где обслуживались исключительно служащие железной дороги; больница для заразных больных на 65 коек с двумя врачами, куда принимались все, кроме венерических больных; хирургическая лечебница при Общине сестёр милосердия Красного Креста с хирургическим и женским отделениями на 12 коек. Были и частные больницы: водолечебница врача Еланцева, куда принимались больные с нервными заболеваниями и сифилисом; лечебница для физических методов лечения врача Иванова, где лечились от внутренних, женских, кожных заболеваний; также лечебница врачей Левенсона и Гершкопфа для лечения женских и хирургических болезней [Там же. С. 275-279].

В Барнауле, где население в годы Первой мировой войны составляло около 60-70 тыс. чел., количество лечебных заведений было меньше, чем в Томске. Здесь работала городская больница с тремя штатными врачами, рассчитанная на 50 мест; Барнаульская городская заозёрная больница имени Балашова с одним штатным врачом на 40 коек, в том числе койками для заразных больных; инфекционная («заразная») больница; Барнаульская городская амбулаторная лечебница с 2 врачами; военный лазарет; родильный дом, который построил на свои средства врач А.И. Смирнов, а в 1915 г. создаётся также железнодорожная больница на 50 коек [1. С. 229, 218, 227; 23].

С началом войны резко увеличивается загруженность медицинских учреждений в Западной Сибири. Так, в середине августа 1914 г. в Барнаульской городской больнице, рассчитанной на 50 мест, число больных в некоторые дни превышало 200 чел. [24. Л. 7, 9]. Поскольку мест в палатах не хватало, больные размещались в коридорах, причём мужчины и женщины вместе [18]. Первая городская больница в Новониколаевске для внутренних и хирургических больных и рожениц, рассчитанная на 50 коек, в годы войны была вынуждена увеличить число коек более чем в два раза. Сомкнутые вместе для экономии пространства койки представляли собой своеобразные нары, на которых тесно лежали больные, укрываясь нередко по паре одним одеялом [25. С. 368].
Предназначенные для местного населения места в лечебных учреждениях, особенно в первые годы войны, зачастую были заняты ранеными воинами и военнопленными. В 1914 г. на 4420 размещённых в Барнауле военнопленных приходилось 1933 больничных дня из общего числа 3060 по городу, что составляло $63,16 \%$ [26. Л. 15-17]. В Новониколаевске в первой половине 1915 г. до 80\% больных в местных больницах составляли пленные и военнослужащие, так что многие слои городского населения оказывались без врачебной помощи [13. С. 210].

Связанный с этим случай широко освещался в газете «Жизнь Алтая» за январь 1915 г.: «С солдаткой Белобородовой, только разрешившейся от бремени случился сильный припадок. Пригласили врача А.И. Смирнова, который диагностировал эпилепсию и, оказав первую медицинскую помощь, посоветовал отвести больную в больницу, т.к. требовался особый уход и наблюдение врача. В одиннадцать часов дня родственники привезли Белобородову в больницу, но там в приёме было отказано в следствие обычного отсутствия мест. Её привезли обратно, но по пути случился припадок и рвота. Больную удалось устроить в больницу только через четыре дня» [27].

Отметим, что недостаток коек в больницах не был характерен только для Новониколаевска и Барнаула, это было общероссийское явление. Подобная ситуация сложилась в результате недооценки масштабов будущей войны и нерационального распределения коек между театром военных действий и внутренними районами страны. Организация медицинского обеспечения России предполагала развернуть на фронтах только одну треть коек, раненые и больные со сроком лечения более шести недель должны были эвакуироваться в тыл. Чтобы понять масштабы проблемы, обратимся к статистическим данным. Так, только с августа 1914 г. по ноябрь 1916 г. включительно с фронта в тыловые лечебно-эвакуационные учреждения России были доставлены 5812935 больных и раненых офицеров и солдат, что в среднем в месяц составляло 116896 чел. В госпиталях тыловых районов находились до окончательного излечения 3273085 чел. (56,3\%) [28. С. 58]. Несмотря на то что во внутренние районы страны должны были эвакуироваться раненые и больные со сроком лечения более шести недель, на практике из-за плохой сортировки эти требования нарушались, и значительная часть легкораненых и больных также отправлялись в тыл.

Остро стояла и проблема лекарственного обеспечения. Уже в начале войны в стране ощущался недостаток медикаментов и хирургических инструментов. Дело в том, что из 118 наименований медикаментов каталога военного времени 80 наименований ввозилось изза границы, в том числе из Германии и Австро-Венгрии [Там же. С. 59]. Чтобы понять масштабы проблемы, необходимо сказать, что до лета 1915 г. в России не производилось даже йода. В дефиците или в полном 
отсутствии в городских больницах были такие лекарства, как хинин и салициловые препараты (аспирин) [1. C. 222].

Не было и анестезии: дорогой кокаин и опий в аптеках не закупались, эфир и хлороформ применялись только при операциях. Единственное, чем были полностью обеспечены медицинские лечебные учреждения, индивидуальные перевязочные пакеты.

Ситуация начала стабилизироваться лишь к концу 1915 г. [29. С. 167]. Петроградский завод военноврачебных заготовлений по приказу начальника санитарной и эвакуационной части А.П. Ольденбургского стал работать в три смены, а Институт экспериментальной медицины обеспечил бесперебойный выпуск вакцин и сывороток. По инициативе принца и на его личные средства были начаты производство йода из морских водорослей, а также сбор лекарственных трав на Кавказе.

Смириться с нехваткой лекарств в условиях, когда тысячам людей требовались ежедневно лекарства, не мог не только принц А.П. Ольденбургский. В течение первой недели октября 1916 г. в Петрограде проходил всероссийский съезд по борьбе с лекарственным голодом и по мобилизации отечественной химикофармацевтической промышленности, в котором участвовали и представители из городов Западной Сибири. На съезде широко освещали современное положение лекарственного вопроса в России, искали способы рационального снабжения русского рынка медикаментами и, наконец, вырабатывали общий план развития русской химико-фармацевтической промышленности.

Там же было выяснено, что русская химикофармацевтическая промышленность способна развиваться самостоятельно, а не как ранее, закупая медикаменты в Германии. На производство лекарств были брошены значительные научные силы. Почти сразу после съезда 18 октября 1916 г. в Барнаульской городской управе состоялось заседание врачебносанитарного совета, на котором вместе с городским головой В.Я. Бирюковым члены совета обсудили организацию товарищества по изготовлению медикаментов [30. Л. 52].

В годы войны в Западной Сибири ощущался не только недостаток медикаментов, но и врачей. Об этом подробно в своём выступлении на заседании первого съезда врачей Томской губернии сообщает хирург Н.М. Руднев. В своём докладе, который назывался «Барнаульская городская больница в настоящее время. Деятельность больницы и условия работы в ней», врач отмечал, что лечебное учреждение приблизительно в течение 4-4,5 лет обслуживалось двумя врачами, 1,52 месяца в начале 1917 г. обслуживалась тремя врачами, а остальное время - одним врачом [1. С. 219]. Н.М. Руднев пояснял, что во многом это было связано с тем, что в военное время один из врачей, а нередко и оба, откомандировывался губернской администрацией или другими властями в Воинское присутствие и на соборный пункт для освидетельствования призываемых. В Омске ситуация с врачами обстояла несколько лучше, однако их число с каждым годом уменьшалось. Если в 1914 г. в городе насчитывалось 37 врачей, то в 1915 г. их количество сократилось до 23 [31. С. 200]. Причиной такого сокращения стало то, что медицинский персонал забирали на фронт, причём зачастую империя даже не стремилась оплатить медицинским работникам дорогу и проживание. Так, например, из далёкой Варшавы старший врач госпиталя телеграммой просил выслать барнаульским сестрам милосердия Маркиной, Будкевич, Шелеповой и Гуляевой, приехавшим в госпиталь Варшавы на свои средства, по 40 руб. [32. Л. 8]. Вскоре в лечебных учреждениях крупных городов Западной Сибири наблюдалась катастрофическая нехватка медицинского персонала. Дело дошло до того, что в феврале 1915 г. гласные Томской городской думы постановили освободить всех городских врачей от призыва в армию [31. С. 203].

Не всё благоприятно обстояло и с питанием пациентов. Говоря о питании больных во время войны, заведующий Барнаульской городской заозёрной больницей врач А.П. Велижанин отмечал, что для больных доставляется недостаточное количество молока и порой вообще не поступает мяса. На недостаточность молока для больных указывал и заведующий Барнаульской городской больницей Барнаула врач Н.М. Руднев. Руднев также сообщает, что приходилось испытывать дефицит хлеба, который иногда даже совсем не доставляли, а иногда привозили полусырой с толстой коркой, который был не пригоден для питания больных [1. С. 218-231].

Отметим, что лечение в сибирских больницах в годы войны было в основном платным. Порядок цен можно понять, рассмотрев цены в Барнаульской городской больнице. Так, стационарные больные за сутки в больнице платили: городские жители - 1 р., иногородние - 1 р. 50 к., служащие фирм - 2 р., железнодорожные служащие - 5 р., исключение делалось для бедных и семей, призванных на войну, которые могли по усмотрению городской управы лечиться бесплатно. Точных предписаний для администрации больницы также не было дано [Там же. С. 221].

Вопросы здравоохранения разные города Западной Сибири решали с разной степенью эффективности. Так, Томску для борьбы с эпидемиями из общегосударственных источников было выделено безвозвратное пособие в размере 220 тыс. руб. Этому способствовала личная поездка томского городского головы доктора Ломовицкого в Петроград к принцу А.П. Ольденбурскому, в ходе которой голова попросил данную сумму. В то же время Омску такая помощь оказана не была, при том что в Омске население было больше [19. С. 6-7].

Несмотря на многочисленные финансовые трудности, сибирские врачи и местные власти предпринимали ряд действенных шагов по борьбе с заразными заболеваниями в городах. Среди таких шагов было, например, 
широкое обсуждение в прессе методов борьбы с заразными заболеваниями.

Так, в газете «Алтайское дело» за 22 августа 1915 г. городским санитарным врачом Новониколаевска была напечатана памятка для населения о мерах предохранения от холеры. В ней сообщалось, что заразиться болезнью можно, употребляя в пищу плохо промытые, испорченные фрукты и овощи, рекомендовалось всякий раз при любом использовании кипятить воду. Кроме того, при первых признаках болезни в газете советовали обращаться к фельдшеру или врачу и не заниматься самолечением [33]. С целью борьбы с эпидемическими заболеваниями и в частности с холерой с 1 августа 1916 г. в Новониколаевске был открыт холерный барак с дезинфекционной камерой и прачечной, организован санитарно-дезинфекционный отряд, продолжилось систематическое прививание населения от оспы. Кроме того, с этой же целью в короткий срок от грязи были очищены площади и улицы города [34. Л. 61].

В марте 1916 г. в Новониколаевске был учреждён институт санитарных попечителей. При этом состоящим попечителями лицам давались самые широкие полномочия. Они могли составлять протоколы в отношении лиц, нарушивших санитарные правила, возбуждать против них судебные преследования, а также принимать надлежащие меры для устранений нарушений [35. Л. 23].

В Барнауле в 1916 г. был принят ряд эффективных мер для борьбы с сыпным тифом. Помещения, где жили беженцы, лишь только появлялись случаи заболевания, освобождались, а они сами переводились в другой дом. Освобожденное помещение мылось, белилось, нары обливались кипятком, жидкостью Смородникова. Переводимые мылись в бане с дезинфекцией и сменой белья. Для того чтобы улучшить санитарное состояние жилищ и извлекать подозрительных больных как можно раньше, врачами города производилось обследование всех помещений, где размещались беженцы, как общежитий, так и городских квартир [1. С. 230-231]. Существенно улучшило эпидемическую ситуацию в Барнауле в 1916 г. переселение 600 беженцев из дома купца Сухова, считавшегося главным очагом инфекции. Эта мера наряду с дезинфекцией помещений способствовала предотвращению дальнейшего роста эпидемии [36].

Таким образом, в первые три года войны медицинское обслуживание населения крупных городов Западной Сибири было организовано неудовлетворительно. Горожане столкнулись с многочисленными эпидемиями заразных заболеваний, источником которых были военнопленные, беженцы и военнообязанные. Нерациональное распределение коек между театром военных действий и внутренними районами страны привели к резкому увеличению загруженности лечебных учреждений города. Освидетельствование воинских чинов и лечение нескольких сотен военнопленных способствовали ухудшению санитарной обстановки в больницах и сокращению неотложных операций. Кроме того, работа лечебных учреждений была осложнена недостатком врачей и медикаментов. Однако, несмотря на тяжесть обстоятельств военного времени, сибирские врачи и местные власти предпринимали многочисленные эффективные шаги по борьбе с заразными заболеваниями и смогли в конечном итоге предотвратить более масштабные эпидемии.

\section{ЛИТЕРАТУРА}

1. Труды первого съезда врачей Томской губернии (9-14 сентября 1917 г.). Томск, 1917. Вып. 1. 269 с.

2. Тихов П.И. Хирургические госпитальные клиники. Томск, 1916. $11 \mathrm{c.}$

3. Рабинович М.С. Из истории Омского военного госпиталя // Известия Омского отделения географического общества СССР. Омск, 1960. Вып. 3. С. 37-43.

4. Рабинович М.С. Роль военных врачей Омска в истории гражданского здравоохранения города до Октябрьской революции // Межвузовская научная конференция. Материалы географической секции. Омск, 1967. С. 113-118.

5. Федотов Н.П., Мендрина Г.И. Очерки по истории медицины и здравоохранения Сибири. Томск, 1975.260 с.

6. История здравоохранения дореволюционной России (конец XVI - начало XX в.). М., 2014. 248 с.

7. Буравцов В.И. К 100-летию Первой мировой войны. Медицинская служба Русской армии в годы Первой мировой войны (сообщение второе - год 1914) // Скорая медицинская помощь. 2014. Т. 15, № 2. С. 31-37.

8. Ерёмин И.А. Забота о больных и раненых войнах в Западной Сибири в годы Первой мировой войны (1914-1918 гг.) // Известия Томского политехнического университета. 2006. Т. 309, № 6. С. 202-205.

9. Семенова К.А. Здравоохранение города Томска: время становления (1860-е - 1919 г.). Томск, 2009.157 с.

10. Гефнер О.В. Медицинская деятельность военных Омска в конце XIX - начале XX в. // Вестник Омского университета. Омск, 1999. Вып. 1. С. $46-50$.

11. Сибирская жизнь (Томск). 1914. 4 окт.

12. Государственный архив Новосибирской области (далее - ГАНО). Ф. Д-97. Оп. 1. Д. 202.

13. Горюшкин Л.М., Бочанова Г.А., Цепляев Л.Н. Новосибирск в историческом прошлом. Новосибирск, 1978.294 с.

14. Врачебно-санитарная хроника города Омска. 1915 г. Омск, 1916.

15. Сибирская жизнь (Томск). 1916. 3 июля.

16. Государственный архив Омской области. Ф. 30. Оп. 1. Д. 28.

17. Омский вестник (Омск). 1915.12 марта.

18. Жизнь Алтая (Барнаул). 1916. 22 окт.

19. Врачебно-санитарная хроника города Омска. 1916 год. Омск, 1917.

20. Дипломированные медики // История Алтая с древнейших времён и до наших дней [интернет портал]. URL: http://starshoes.su/zdravoohranenie/diplomirovannyie-mediki.html, свободный (дата обращения: 10.01.15).

21. Памятная книжка Акмолинской области на 1916 г. Омск, 1916.

22. Адресно-справочная книжка «Весь Томск» на 1912-1913 гг. Томск, 1913. 
23. Саета В.А. Барнаул. Прошлое и настоящее (1730-2008) // Краеведческий портал Алтайской краевой универсальной научной библиотеки им. В.Я. Шишкова [Официальный сайт]. URL: http://altlib.ru/files/cd/barnaulsaeta/002.html, свободный (дата обращения: 10. 01. 2015).

24. Государственный архив Алтайского края (далее - ГААК). Ф. 51. Оп. 1. Д. 219.

25. История города. Новониколаевск-Новосибирск: исторические очерки : в 2 т. Новосибирск, 2005. Т. 1. 864 с.

26. ГААК. Ф. 219. Оп. 1. Д. 64.

27. Жизнь Алтая (Барнаул). 1915. 11 янв.

28. Будко А.А., Селиванов Е.Ф. Военная медицина в войне с Японией в 1904-1905 гг. // Военно-исторический журнал. 2004. № 6. С. 57-62.

29. Ерёмин И.А. Томская губерния как тыловой район России в годы Перовой мировой войны (1914-1918 гг.). Барнаул, 2005. 276 с.

30. ГААК. Ф. 219. Оп. 1. Д. 16.

31. Чудаков О.В. Социально-культурная деятельность органов Городского самоуправления в западной Сибири в годы Первой мировой войны (1914 - февраль 1917 года) // Культурологические исследования в Сибири. № 3. Омск, 2005.

32. ГААК. Ф. 219. ОП. 1. Д. 1031.

33. Алтайское дело (Барнаул). 1915. 22 авг.

34. ГАНО. Ф. Д-97. Оп. 1. Д. 215.

35. ГАНО. Ф. Д-97. Оп. 1. Д. 161.

36. Жизнь Алтая (Барнаул). 1916. 4 фев.

Shumilova Elina E. Institute of History of Siberian Branch of Russian Academy of Sciences (Novosibirsk, Russia). E-mail: e-shumilova@yandex.ru

THE FIRST WORLD WAR AND THE LEVEL OF MEDICAL CARE IN THE CITIES OF WESTERN SIBERIA (1914-1917).

Keywords: medicine; epidemic; Western Siberia; the First World War; Novonikolayevsk; Barnaul; Tomsk; Omsk.

The article attempts for the first time to comprehensively analyze the impact of the First World War on the state of medical care in the rear of the large cities of Western Siberia in 1914-1917. The choice of research topic is not accidental: the majority of modern scientific articles is devoted to military medicine and care of the sick and wounded soldiers, and period of the First World War in the development of civil medicine practically does not stands out, and therefore, complete conclusions about how the war has affected on health care of citizens remaining in the rear were not made. The article consists of three parts. At the beginning of the article the author makes a brief historiographic review of pre-revolutionary, Soviet and contemporary literature on the subject, and gives substantiation of its relevance. Then the main part of the paper attempts to describe the epidemiological situation in the cities of Western Siberia in 1914-1917 and to highlight the causes of its deterioration. Finally, in the third part of the article the author discusses the steps of local authorities in the fight against infectious diseases and on the basis of the analysis and synthesis of information from archival sources and literature makes the conclusions. Firstly, the author concludes that in the first year of the war many epidemics of infectious diseases such as typhoid and typhus, measles, syphilis and widely spread dysentery swamped Siberian cities. Secondly, it is emphasized that the source of these diseases often were prisoners of war, refugees and soldiers of the Russian army. Thirdly, it is noted that the intended spaces for the local population in hospitals especially in the first years of the war were often occupied by aforecited social groups, because originally there were not enough hospitals. Fourthly, among the main causes of the unfavorable epidemiological situation were: lack of doctors, medicines and medical instruments due to the leaving personnel to the war and an end of import from enemy countries, unsanitary living conditions of internally displaced persons, malnutrition of patients, as well as under-funding of medical institutions. At the end, the author concludes that during the war medical care of cities such as Omsk, Tomsk, Barnaul and Novonikolayevsk was organized poorly. However, the author notes that the Siberian doctors and local authorities had taken many effective measures to combat infectious diseases and were able to prevent a large-scale epidemic. It should be noted that the issues discussed in the article allows partially fill the "white spots" in the history of the Siberian everyday life.

\section{REFERENCES}

1. Chistyakov, P.I. (ed.) Trudy pervogo s"ezda vrachey Tomskoy gubernii (9-14 sentyabrya 1917 g.) [Proceedings of the First Congress of Doctors of Tomsk Province (September 9-14, 1917)]. Vol. 1. Tomsk: [s.n.].

2. Tikhov, P.I. (1916) Khirurgicheskie gospital'nye kliniki [The surgical hospital clinic]. Tomsk: [s.n.].

3. Rabinovich, M.S. (1960) Iz istorii Omskogo voennogo gospitalya [From the history of the Omsk Military Hospital]. Izvestiya Omskogo otdeleniya geograficheskogo obshchestva SSSR. 3. pp. 37-43.

4. Rabinovich, M.S. (1967) [The role of military doctors in the history of the Civil Health Care in Omsk before the October Revolution]. Mezhvuzovskaya nauchnaya konferentsiya. Materialy geograficheskoy sektsii [Interuniversity Scientific Conference. Proc. of the Geographic Section]. Omsk. pp. 113118.

5. Fedotov, N.P. \& Mendrina, G.I. (1975) Ocherki po istorii meditsiny i zdravookhraneniya Sibiri [Essays on the History of Medicine and Health in Siberia]. Tomsk: Tomsk State University.

6. Poddubnyy, M.V., Egorysheva, I.V., Sherstneva, E.V., Blokhina, N.N. \& Goncharova, S.G. (2014) Istoriya zdravookhraneniya dorevolyutsionnoy Rossii (konets $X V I-$ nachalo $X X$ v.) [The history of the health care in the Pre-Revolutionary Russia (the late 16th - early 20th centuries)]. Moscow: GEOTAR-Media.

7. Buravtsov, V.I. (2014) K 100-letiyu Pervoy mirovoy voyny. Meditsinskaya sluzhba Russkoy armii v gody Pervoy mirovoy voyny (soobshchenie vtoroe - god 1914) [On the 100th anniversary of the First World War. Medical service in the Russian army during the First World War (the second message, 1914)]. Skoraya meditsinskaya pomoshch'. 15(2). pp. 31-37.

8. Eremin, I.A. (2006) Zabota o bol'nykh i ranenykh voynakh v Zapadnoy Sibiri v gody Pervoy mirovoy voyny (1914-1918 gg.) [Caring for the sick and wounded in the wars in Western Siberia in the years of the First World War (1914-1918)]. Izvestiya Tomskogo politekhnicheskogo universiteta Bulletin of the Tomsk Polytechnic University. 309(6). pp. 202-205.

9. Semenova, K.A. (2009) Zdravookhranenie goroda Tomska: vremya stanovleniya (1860-e - 1919 g.) [Health Care of Tomsk: The time of formation (1860-1919)]. Tomsk: Tomsk State University.

10. Gefner, O.V. (1999) Meditsinskaya deyatel'nost' voennykh Omska v kontse XIX - nachale XX vv. [The medical activities of the military in Omsk in the late 19th - early 20th centuries] Vestnik Omskogo universiteta - Herald of Omsk University. 1. pp. 46-50.

11. Sibirskaya zhizn'. (1914) 4th October.

12. The State Archives of Novosibirsk Region (GANO). Fund D-97. List 1. File 202.

13. Goryushkin, L.M, Bochanova, G.A. \& Tseplyaev, L.N. (1978) Novosibirsk v istoricheskom proshlom [Novosibirsk in its historical past]. Novosibirsk: Nauka.

14. Vrachebno-sanitarnaya khronika goroda Omska 1915 [Medical-Sanitary Chronicle of Omsk, 1915]. (1916)

15. Sibirskaya zhizn'. (1916) 3rd July. 
16. The State Archivs of Omsk Region. Fund 30. List 1. File 28.

17. Omskiy vestnik. (1915) 12th March.

18. Zhizn' Altaya. (1916) 22nd October.

19. Vrachebno-sanitarnaya khronika goroda Omska 1916 [Medical-Sanitary Chronicle of Omsk, 1916]. (1917)

20. Istoriya Altaya. (n.d.) Diplomirovannye mediki [Qualified doctors]. [Online] Available from: http://starshoes.su/zdravoohranenie/diplomirovannyiemediki.html. (Accessed: 10th January 2015).

21. Sobolev, M.N. (ed.) (1916) Pamyatnaya knizhka Akmolinskoy oblasti na $1916 \mathrm{~g}$. [The memorial book of Akmola region in 1916]. Omsk: Regional Typography.

22. Chavykin, G.V. (ed.) (1913) Ves' Tomsk na 1912-1913 gg. [The Whole Tomsk. 1912-1913]. Tomsk: [s.n.]

23. Saeta, V.A. (n.d.) Barnaul. Proshloe i nastoyashchee (1730-2008) [Barnaul. The past and the present (1730-2008)]. [Online] Available from: http://altlib.ru/files/cd/barnaulsaeta/002.html. (Accessed: 10th January 2015).

24. The State Archives of the Altai Territory (GAAK). Fund 51. List 1. File 219.

25. Kosenkov, A.F. (ed.) (2005) Istoriya goroda. Novonikolaevsk-Novosibirsk: istoricheskie ocherki: $v 2 t$. [The history of the city. NovonikolayevskNovosibirsk: Historical essays. In 2 vols]. Vol. 1. Novosibirsk: Ist. nasledie Sibiri.

26. The State Archives of the Altai Territory (GAAK). Fund 219. List 1. File 64

27. Zhizn' Altaya. (1915) 11th January.

28. Budko, A.A. \& Selivanov, E.F. (2004) Voennaya meditsina v voyne s Yaponiey v 1904-1905 gg. [Military medicine in the war with Japan of 19041905]. Voenno-istoricheskiy zhurnal. 6. pp. 57-62.

29. Eremin, I.A. (2005) Tomskaya guberniya kak tylovoy rayon Rossii v gody Perovoy mirovoy voyny (1914-1918 gg.) [Tomsk province as a Russian rear area during World War I (1914-1918)]. Barnaul: Barnaul State Pedagogical University.

30. The State Archives of the Altai Territory (GAAK). Fund 219. List 1. File 16.

31. Chudakov, O.V. (2005) Sotsial'no-kul'turnaya deyatel'nost' organov Gorodskogo samoupravleniya v zapadnoy Sibiri v gody Pervoy mirovoy voyny (1914 - fevral' 1917 goda) [Socio-cultural activities of the Municipal governments in Western Siberia in World War I (1914 - February 1917)]. Kul'turologicheskie issledovaniya v Sibiri. 3.

32. The State Archives of the Altai Territory (GAAK). Fund 219. List 1. File 1031.

33. Altayskoe delo. (1915) 22nd August.

34. The State Archives of Novosibirsk Region (GANO). Fund D-97. List 1. File 215

35. The State Archives of Novosibirsk Region (GANO). Fund D-97. List 1. File 161

36. Zhizn' Altaya. (1916) 4th February. 